Klockmann's Lehrbuch der Mineralogie

Neu herausgegeben von Prof. Paul Ramdohr. Dreizehnte durohgesehene Auflage. Pp. xii +674 . (Stuttgart : Ferdinand Enke, 1948.) 50 D. marks.

$\mathrm{T}$ HIS book has become in Germany the classic exposition of mineralogical science and can be compared most directly with its American counter. part, namely, Dana's text-book published in 1932. Prof. P. Ramdohr's careful revision embodies all the advantages of a descriptive system based upon the exact measurements of the crystallographer, the chemist and the physicist. The sections on crystal form, the fine structure of crystals, the physics and chemistry of minerals and crystals, and the study of their paragenesis form an imposing prelude to the systematic description of more than twenty-five hundred mineral species.

Based upon the pioneer work of the chemist and crystallographer a century ago, these are arranged in an order that has, in its broadest aspect, undergone only comparatively minor changes during the past century. The silicates, for example, upon which so much light has been shed by the $\mathbf{X}$-ray analysis of their crystal structures, can now be arranged in a manner that corresponds to their stereochemistry rather than to a series of hypothetical silicic acids. Further systematic X-ray analysis, particularly of the sulphide ores and of the lesser known sulphates and phosphates, will eventually lead to a more rational order of arrangement of the entire mineral kingdom and of related inorganic compounds.

We may expect, also, that the examination of polished ore surfaces in reflected polarized light, a method applied with outstanding success by Prof. Ramdohr in differentiating minerals and studying their order of formation and interrelations in metallic ores, will help to throw more light upon the conditions of formation of mineral veins. F. A. BANNISTER

\section{Plants and Environment}

A Textbook of Plant Autecology. By R. F. Daubenmire. Pp. xiii +424. (New York: John Wiley and Sons, Inc.; London: Chapman and Hall, Ltd., 1947.) 36s. net.

7 HIS book is based on the author's experience of lecturing on the relation between plants and their environment to mixed groups of students, including both those whose main interest is academic and students of applied botany, and he keeps in mind the needs of the latter throughout. This has sometimes led to simplification at the expense of accuracy, as in the statement (p. 372) that "such hybridisation" (exchange of genes between ecotypes) "occasionally produces new ecotypes. Thus Spartina Tounsendii, a natural cross between $S$. stricta and $S$. alterniflora, kills out both parents in competition. ...."

The book includes chapters on soil, water, temperature, light, atmosphere, biotic and fire factors, followed by a short account of "The Environmental Complex" and a chapter on "Ecologic Adaptation and Evolution". The treatment is somewhat uneven. The accounts of soil, water, temperature and light are adequate, and the consideration of wind and fire as ecological factors covers ground which is often neglected. The discussion of biotic factors and the last two chapters are sketchy. A student relying solely on this book for instruction in ecology, as students of forestry and agriculture well might, would lack a reslization of the importance of interaction between members of a community.
There are a number of errors in the numerical examples and a number of inaccurate statements, for example, in the discussion of $p H$ (p. 45), "total number of $H$ plus $\mathrm{OH}$ ions remains constant". The book is well illustrated; the diagrams of seasonal water changes in the soil are especially apt. The copy received for review had five paragraphs from pp. 345-6 repeated under a different heading on pp. 348 $\rightarrow$.

P. GREIG-SMITH

\section{Outlines of Physical Chemistry}

By Prof. Farrington Daniels. Pp. viii +713 . (New York : John Wiley and Sons, Inc.; London : Chap. man and Hall, Ltd., 1948.) 40s. net.

CHIS is a completely new version of the wellknown book by Getman and Daniels, and provides an introductory course with emphasis on practical examples. A large number of problems are worked out in the text, and many more are given at the ends of the chapters, answers to some of these being provided. Some of the more elementary material has been omitted. More difficult parts of the subject are given in an appendix. Some literature references are given, together with lists of books at the ends of chapters; these are nearly all American.

The subjects dealt with are those taught in modern courses, and the standard is higher than that usually found in elementary books on the subject. Great care has been taken to make the text clear, and the numerous good illustrations are a help to the understanding. The curves are based on actual results. Modern developments are included, and, in addition to the usual topics, there are chapters on quantum theory, photochemistry, and atomic and nuclear structure. In the thermodynamics sections the American symbols and names are used.

There is little doubt that Prof. F. Daniels is right in his thesis that physical chemistry is best learnt in relation to numerical exercises, and his book is a very sound and attractive course.

Qualitative Analysis and Chemical Equilibrium

By Prof. T. R. Hogness and Prof. Warren C. Johnson. Third edition. Pp. xv+553. (New York: Henry Holt and Co. ; London: George G. Harrap and Co., Ltd., 1947.) $18 s$.

THE authors express their indebtedness, among others, to J. Stieglitz, and this book might be briefly described as a modern form of his "Qualitative Chemical Analysis": Part I (285 pages) is wholly devoted to a theoretical study of chemical equilibrium and other physical concepts which are the foundations of analysis. The authors, in this edition, have amended their presentation in the light of experience and criticism, and have included the application of recently discovered principles. This section is well done and affords in simple language a clear account of modern theory.

The practical section (Part 2) describes the procedures and techniques for the analysis of mixtures containing the customary anions and cations. It has a novel feature-semi-micro methods only are used. The authors, from their experience, dilate on the advantages of these methods and predict their widespread adoption. The appendixes contain a section on mathematical operations, and various tables, including one of the physical properties of compounds usually present in mixtures for analysis. This is a most interesting book for all concerned with instructional analysis.
G. F. 